\title{
Characterization of Anionic Reverse Micelles Formulated on Biobased Solvents as Replacing Conventional Nonpolar Organic Solvents
}

\author{
Mauricio Oyarzun, Guillermo Oliva, R. Dario Falcone,* and Paulina Pavez* \\ Cite This: ACS Sustainable Chem. Eng. 2020, 8, 5478-5484 \\ Read Online
}

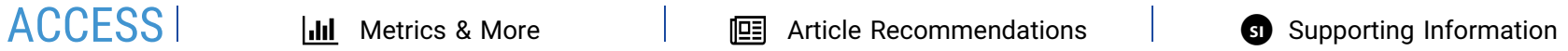

ABSTRACT: Two reverse micelles (RMs) employing 1,4-bis-2ethylhexylsulfosuccinate (AOT) and two biobased solvents, $p$ cymene (p-cym) or limonene (lim), have been formulated with the aim to obtain systems more environmentally friendly. Both RMs were studied by using different techniques such as dynamic light scattering (DLS) and ${ }^{1} \mathrm{H}$ NMR. Additionally, spectroscopy techniques were used to obtain information such as critical micellar concentration and aggregation number of the system investigated. Our results show that both biobased solvents can be used to generate AOT RMs. Interestingly, even the maximum amount of water dispersed are similar for both RMs, and the sizes of the systems are not identical, being that the RMs are formulated in lim larger than in p-cym. Both the biobased solvent and RMs show interaction of the entrapped water and the interface; however, this interaction is different depending on the solvent employed to prepare the RMs. Thus, the interaction water-surfactant at the interface is weaker in p-cym/AOT than in lim/AOT RMs. We think that the different penetration of the external solvent to the interfacial region is the main reason for the facts observed. In this sense, the polarity of these biobased solvents could explain why the penetration of both biobased solvents is different, making the p-cym/AOT RMs less interactive and, therefore, with smaller droplets sizes values. In summary, the different capacities of these biobased solvents to penetrate into the AOT interface allow us to obtain a new interface with peculiar characteristics and therefore with diverse applications.

KEYWORDS: Reverse micelles, AOT, Biobased solvents, p-cymene, limonene

\section{INTRODUCTION}

Reversed micelles (RMs) are organized systems of nanometric size formed by three components, i.e., a polar solvent (generally water), a surfactant, and some nonpolar solvent which form a thermodynamically stable and optically transparent solution. ${ }^{1}$ Due to the diverse applications of $\mathrm{RMs},{ }^{1,2}$ in the past decade there has been much interest in assessing the nature of the surfactants and of nonpolar solvents that can be part of these organized systems. ${ }^{3-5}$ One of the surfactants more often used to form RMs is the anionic sodium 1,4-bis-2ethylhexylsulfosuccinate (AOT, Scheme 1). ${ }^{1}$ Diverse RMs using AOT and different organic nonpolar solvents, aromatic and aliphatic, have been reported. ${ }^{6}$ The results show that the quantity of water solubilized in these systems can be up to $W_{0}$ $=\left[\mathrm{H}_{2} \mathrm{O}\right] /[$ surfactant $] \sim 60$, depending on the nonpolar solvent and temperature. ${ }^{6}$ Nevertheless, replacing these toxic and volatile petroleum-based solvents (used as nonpolar solvents in RMs) by more environmentally friendly alternatives is a challenge to generate RMs more biocompatible and with less impact on the environment. ${ }^{7,8}$ Given the above, recently two nontoxic lipophilic oils such as methyl laurate (ML) and isopropyl myristate (IPM) have been used to formulate different environmentally friendly RMs. The formation of the corresponding AOT RMs and some properties of these system such as $W_{0}$, droplets size values, CMC, and $N_{\text {agg }}$ among others, depending strongly on the chemical structure of the external solvent. $^{3,4,7}$ However, the search for new nonpolar and nontoxic solvents for the elaboration of more RMs still remains of interest. In this context, solvents derived from biomass, named as biobased solvents, could be a good alternative for this purpose. These new solvents are obtained from natural resources (such as corn, beans, citrus fruit peels, among others). ${ }^{9}$ Some examples include, glycerol, ethyl lactate, $p$-cymene (p-cym), and limonene (lim), among others. ${ }^{10}$ Due to its peculiar characteristics, these biobased solvents have shown to be much safer solvents for both human beings and

Received: November 6, 2019

Revised: March 18, 2020

Published: March 25, 2020 
Scheme 1. Structures of the Surfactant AOT, the Biobased Solvents (p-cym and lim), and the Molecular Probes (QB and Safranine T)<smiles>CCCCC(CC)COC(=O)CC(I)S(=O)(=O)OCC(CC)CCCC</smiles>

AOT<smiles>Cc1ccc(C(C)C)cc1</smiles>

p-cym<smiles>C=C(C)C1CC=C(C)CC1</smiles>

$\lim$<smiles>C[n+]1cccc2cccc(O)c21</smiles>

QB<smiles>Cc1cc2nc3cc(C)c(N)cc3[n+](-c3ccccc3)c2cc1N</smiles>

Safranine T the environment, in comparison with those petroleum-based solvents. ${ }^{11}$ In particular, p-cym and lim come from citrus fruit peels, and they are considered as low polar solvents with weak hydrogen bond basicity. Both of them have optimal characteristics as solvents capable of successfully replacing nonpolar petroleum-based solvents. ${ }^{12}$ To date, there are several reports indicating the benefits of using biobased solvents. ${ }^{13,14}$ Nevertheless, the use of this kind of solvent in a compartmentalized system (such as reverse micelles) has not been explored.

Therefore, considering that the change in the nature of the external solvent can affect the properties in the RMs interface, we wanted to evaluate the use of two biobased solvents derived from citrus fruit (p-cym and lim) as an external solvent in AOT RMs. In this sense, four objectives are raised: (i) study the use of p-cym and lim to formulate AOT RMs; (ii) obtain the critical micellar concentration (CMC) for p-cym and lim/ AOT/water RMs by UV-vis and emission spectroscopy; (iii) evaluate the water encapsulation and the water- interface interaction by dynamic light scattering (DLS) and ${ }^{1} \mathrm{H}$ NMR in both AOT RMs; (iv) obtain the $N_{\mathrm{agg}}$ for both RMs by emission spectroscopy; and (iv) compare our results with AOT RMs prepared in benzene and $n$-heptane, among others.

\section{RESULTS AND DISCUSSION}

In the present work we evaluate two different biobased nonpolar solvents ( $\mathrm{p}$-cym and lim) to generate biocompatible RMs, using the well-known anionic surfactant AOT. In this sense, the mixture of the anionic surfactant and the biobased solvents were explored, first in the absence of water and later with addition of water. In absence of polar solvent, AOT showed large solubility in both biobased solvents, at least until
$0.2 \mathrm{M}$. Next, we explored if the presence of water on the mixture allowed us to generate stable homogeneous solutions. As it can be observed in Figure S1, transparent and homogeneous solutions were obtained in both biobased systems when the surfactant was present, but turbid and opalescent solutions formed when AOT was absent and the biobased solvents were only mixed with water. Table 1

Table 1. Comparison of $W_{0}^{\max }$ Values Reached by AOT RMs $\left([\mathrm{AOT}]=0.2 \mathrm{M} ; \mathrm{T}=25{ }^{\circ} \mathrm{C}\right)$

$\begin{array}{ll}\text { nonpolar solvent } & W_{0}{ }^{\max } \\ n \text {-heptane } & 50^{a} \\ \text { cyclohexane } & 21^{a} \\ \text { lim } & 17 \\ \text { p-cym } & 17 \\ \text { toluene } & 12^{a} \\ \text { benzene } & 12^{a}\end{array}$

${ }^{a}$ Data obtained from ref 15.

summarizes the $W_{0}^{\max }$ (the maximal $\left[\mathrm{H}_{2} \mathrm{O}\right]$ dissolved) values obtained in both biobased systems. Larger values of $W_{0}$ were not possible to obtain due to when more water is added a turbid solution is detected (Figure S2). Additionally, traditional nonpolar solvents used to form AOT RMs are included in Table 1 . Thus, a $W_{0}^{\max }$ value of 17 was obtained in both biobased/AOT/water solutions, and interestingly, they were able to dissolve more water than RMs formulated in benzene and toluene. ${ }^{15}$

It is interesting to investigate if some property of the nonpolar solvent has influence on the amount of water content. In this sense, Abuin et al. considered the polarity/ 
polarizability parameter $\left(\pi^{*}\right)^{16}$ of the external solvent to explain the $W_{0}^{\max }$ values reached in different aqueous AOT RMs. ${ }^{15}$ In Figure 1, we plot several $W_{0}{ }^{\max }$ values for AOT RMs included our data.

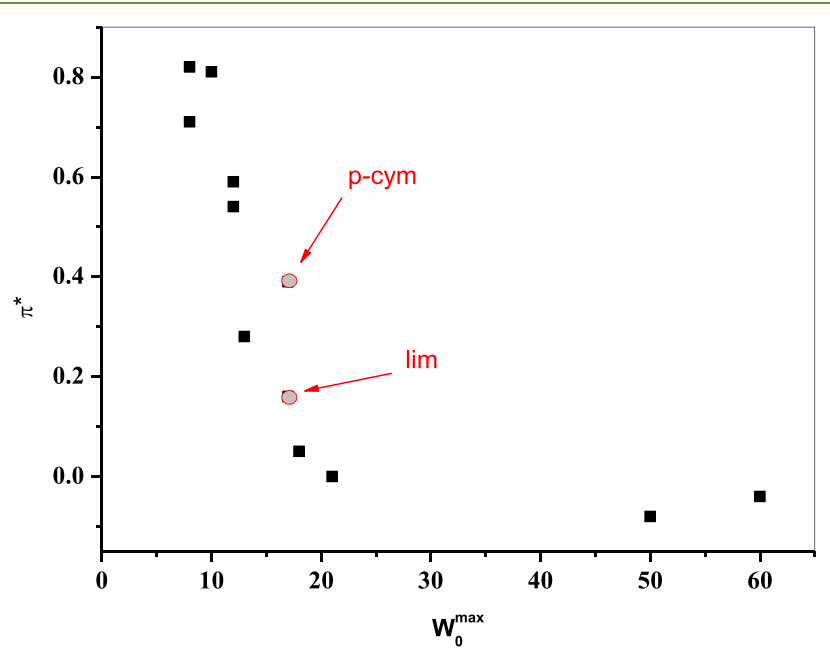

Figure 1. Profile obtained between the $W_{0}{ }^{\max }$ values corresponding to AOT RMs and the polarity/polarizability parameter $\left(\pi^{*}\right)$ of nonpolar solvent used. Data obtained from ref 15 .

As it was observed, when the nonpolar solvent has a very low $\pi^{*}$ value, the AOT RMs can disperse a large amount of $\left[\mathrm{H}_{2} \mathrm{O}\right]$. In our cases, $\mathrm{p}$-cym and lim have intermediate values between the classical aliphatic solvent $n$-heptane and the aromatic benzene or toluene.

In order to characterize these novels RMs, we used two molecular probes to obtain valuable information. Thus, the absorption probe $\mathrm{QB}$ and the fluorescent probe Safranine $\mathrm{T}$ were selected.

QB. The microenvironment of these novel RMs was explored using the very sensitive molecular probe $\mathrm{QB} .{ }^{17} \mathrm{QB}$ is an absorption probe that monitors simultaneously the polarity and the hydrogen bond donor ability through the exploration of their two bands, $\mathrm{B}_{1}$ and $\mathrm{B}_{2}$, respectively. Similar methodology was used to investigate different AOT RMs. ${ }^{18-20}$

Figure 2 shows the plot of the $\mathrm{QB}$ behavior as a function of [AOT $]$ in p-cym/AOT RMs solution evaluated at $W_{0}=0$. We performed the absorption experiments varying the $[\mathrm{AOT}]$ in the range of $0-0.2 \mathrm{M}$ due to the fact that $\mathrm{QB}$ is perfectly soluble in neat p-cym. A similar procedure was performed for the lim/AOT system (results not shown). Figure 2 shows that both $B_{1}$ and $B_{2}$ bands shift to lower wavelengths when the amount of AOT increases. This fact denotes a rise in the polarity around the QB. Moreover, taking into account that an isosbestic point in the absorption profiles is not detected, $\mathrm{QB}$ is located exclusively in the interface of the RMs when the system is formed. ${ }^{18-20}$ Similar results were obtained for $\lim /$ AOT RMs.

The profile of the $\lambda \mathrm{B}_{1}$ maximum band (as polarity sensor) obtained at different $[\mathrm{AOT}]$ for both biobased solvent/AOT systems is plotted in Figure S3. Additionally, the corresponding CMC values for both AOT systems were determined from these data. Table 2 summarizes the data collected using $\mathrm{QB}$ as the molecular probe. As it was observed, CMC values of $10^{-3}$ $\mathrm{M}$ were obtained in both RMs, which are similar to those reported for AOT RMs formulated in solvents such as benzene or $n$-heptane. ${ }^{21}$

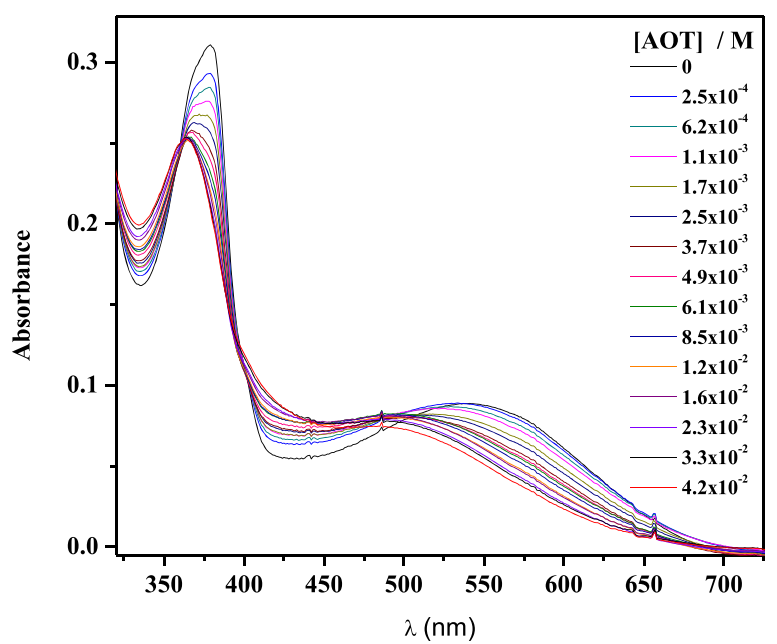

Figure 2. Absorption spectra of $\mathrm{QB}$ varying the $[\mathrm{AOT}]$ in $\mathrm{p}-\mathrm{cym} /$ AOT RMs in the absence of water $\left(W_{0}=0\right)$. $[\mathrm{QB}]=3 \times 10^{-4} \mathrm{M}$.

Table 2. CMC Values of p-cym/AOT and lim/AOT RMs Obtained from $\mathrm{QB}$ and ST Spectroscopic Behavior at $W_{0}=$ o

\begin{tabular}{lcc}
\multicolumn{1}{c}{$\mathrm{RMs}$} & $\mathrm{QB}^{a}$ & $\mathrm{ST}^{b}$ \\
$\mathrm{p}-\mathrm{cym} / \mathrm{AOT}$ & $2.4 \pm 0.5 \times 10^{-3} \mathrm{M}$ & $3.2 \pm 0.7 \times 10^{-3} \mathrm{M}$ \\
$\lim / \mathrm{AOT}$ & $2.2 \pm 0.4 \times 10^{-3} \mathrm{M}$ & $2.5 \pm 0.8 \times 10^{-3} \mathrm{M}$
\end{tabular}

${ }^{a}$ Mean value obtained from spectral changes of $B_{1}$ band (Figure S3). ${ }^{b}$ Mean value obtained from stock shift (Figure S5).

Safranine T. We also explored the behavior of the florescence probe Safranine T (ST) in both RMs. As a sensor of the formation of the organized media, the stock shift of ST was evaluated varying the $[\mathrm{AOT}] .^{22-25}$ Figure 3 shows the

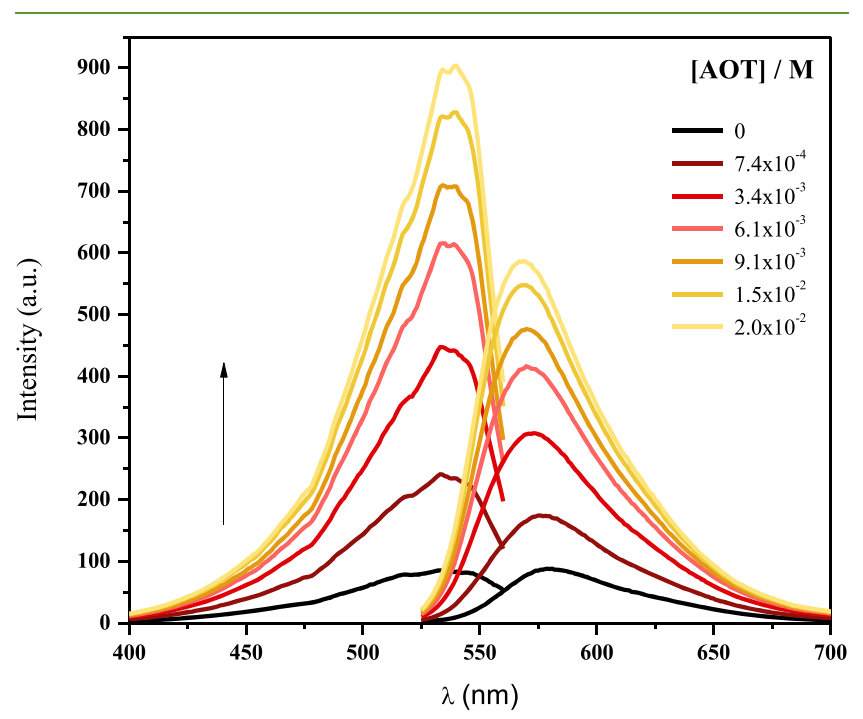

Figure 3. ST emission and excitation spectra varying the $[\mathrm{AOT}]$ in $\mathrm{p}$ cym $/$ AOT RMs. $W_{0}=0$. $[\mathrm{ST}]=2 \times 10^{-6} \mathrm{M}$. $T=25^{\circ} \mathrm{C}$.

emission and excitation bands of $\mathrm{ST}$ in $\mathrm{p}$-cym/AOT RMs varying $[\mathrm{AOT}]$ at $W_{0}=0$. A similar plot for lim/AOT RMs is included in the Supporting Information section (see Figure S4). The values of the stock shift of ST (defined as $\Delta \nu$ ) in both systems is plotted in Figure S5A and B. From this figure, it can also be seen that the CMC values can be obtained (see 
values in Table 2). Similar CMC values between ST and QB were obtained.

DLS. Considering the CMC values obtained from the molecular probes $\mathrm{QB}$ and $\mathrm{ST}$, the droplet sizes of both biobased solvents/AOT solutions at $[\mathrm{AOT}]>10^{-3} \mathrm{M}$ by DLS technique were evaluated. Figure 4 shows the diameter $\left(D_{\text {app }}\right)$

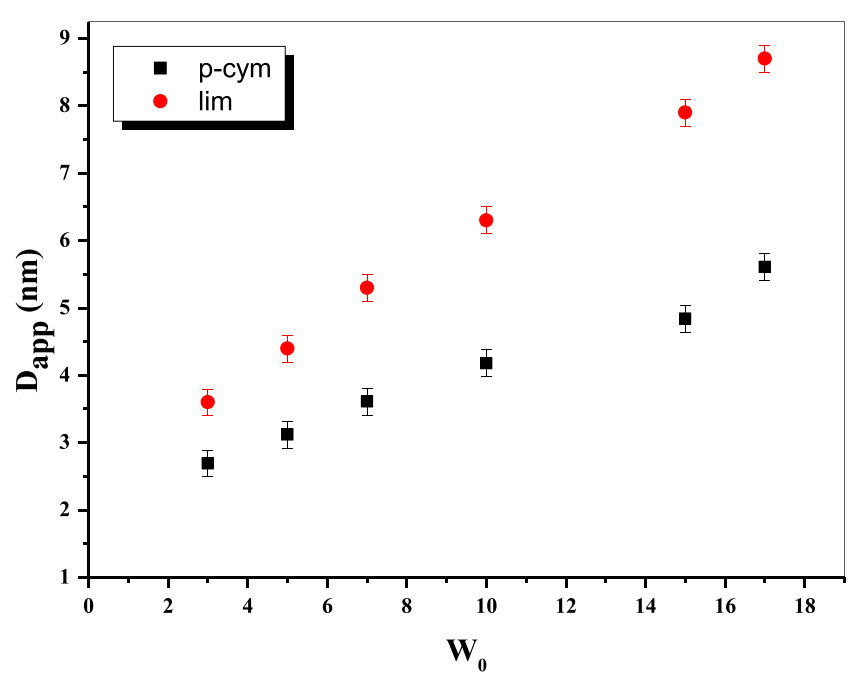

Figure 4. Effect of the water content $\left(W_{0}\right)$ on the $D_{\text {app }}$ values in p$\operatorname{cym} / \mathrm{AOT} /$ water RMs $(\boldsymbol{\square})$ and $\mathrm{lim} / \mathrm{AOT} /$ water RMs $(\bullet) . T=25$ ${ }^{\circ} \mathrm{C}$. $[\mathrm{AOT}]=0.2 \mathrm{M}$.

values of the droplets acquired in the biobased solvents/AOT solutions at $[\mathrm{AOT}]=0.2 \mathrm{M}$ varying the water content. Additionally, the polydispersity index (PDI) values obtained for these measurements are included in Table S1. As it can be observed, only one population in all cases was detected. Additionally, small PDI values (Table S1) were obtained, confirming the uniformity of the organized media formed.

As it is observed from Figure 4, an increase in the droplets sizes and linear tendency in both RMs is detected. Interestingly, the sizes are not identical for both RMs, being that the RMs formulated in lim larger than in p-cym. Additionally, the differences in size appear more important when the water content increases. Thus, when $W_{0}=3$, the droplets size for p-cym/AOT RMs is $2.7 \mathrm{~nm}$ and for lim/AOT RMs is $3.6 \mathrm{~nm}$. At a large $W_{0}$, e.g., at $W_{0}=17$, the sizes are 5.6 and $8.7 \mathrm{~nm}$, respectively.

The DLS data exposed the sizes of the biobased AOT RMs, which were interpreted taking into account the magnitude of the external solvent penetration toward the interfacial zone. It is known that if the solvent can penetrate the interface, it alters the interfacial organization and, in consequence, the size. Thus, we think that $\mathrm{p}$-cym can penetrate more than lim, altering the volume of the hydrocarbon region $(v)$, changing the effective packing parameter $(p)$ of the surfactant. This parameter is determined by the chemical structure of the amphiphile as $p=$ $v / a l_{c}$, where $l_{c}$ is the length of the hydrocarbon chain and $a$ is the area of polar headgroup of the surfactant. ${ }^{26}$ Consequently, if some factor on $p$ is altered, the droplet size changes. For example, a reduction on $p$ is suggested when the RM sizes increase. $^{27,28}$ Thus, in our RMs an increase in the biobased solvent penetration increase the factor $v$ (decreasing $p$ ) and produce smaller droplets. In this sense, AOT RMs formulated in traditional solvents (aromatic and aliphatic) or in biocompatible solvents (IPM and $\mathrm{ML})^{3}$ showed similar behavior to the present work. Moreover, as it will be demonstrated in the next sections, this phenomenon also alters the interfacial properties of the RMs.

We believe that the penetration of the external solvent is a crucial factor to alter the micellar interface. To reinforce this idea, we determined the aggregation numbers $\left(N_{\mathrm{agg}}\right)$ of both biobased solvent/AOT RMs at equal $W_{0}$ (Table 3) using the well-known methodology ${ }^{29}$ by emission spectroscopy using the couple $\mathrm{Ru}(\mathrm{bpy})_{3} \mathrm{Cl}$ and $\mathrm{K}_{3} \mathrm{Fe}(\mathrm{CN})_{6}$. For a detailed procedure see Figures S6 and S7.

Table 3. Aggregation Number $\left(N_{\mathrm{agg}}\right)$ Values Obtained for the Biobased AOT RMs. $T=25{ }^{\circ} \mathrm{C}$. $W_{0}=10$.

\begin{tabular}{crc} 
RMs & $d_{\text {app }}(\mathrm{nm})^{a}$ & \multicolumn{1}{c}{$N_{\text {agg }}$} \\
$\mathrm{p}$-cym/AOT/water & $4.2 \pm 0.4$ & $134 \pm 3$ \\
$\lim / \mathrm{AOT} /$ water & $6.3 \pm 0.4$ & $189 \pm 6$ \\
${ }^{a}$ Data obtained at $W_{0}=10$ from Figure 4. & \\
\hline
\end{tabular}

As can be seen, at $W_{0}=10$ the RMs formulated in $\lim$ present a greater amount of AOT monomers (large $N_{\text {agg }}$ ) than p-cym/AOT RMs. Assuming that both biobased solvent/AOT RMs are practically spherical, we think that the differences of the droplet sizes suggest a dissimilar interfacial conformation. Thus, as p-cym penetrates more, the interface needed less surfactant molecules to entrap water. ${ }^{3}$

${ }^{1} \mathrm{H}$ NMR. Our systems present several protons sensitive to the microenvironment, as displayed in Figures S8 and S9. In this sense, we monitored them as a function of the water content. Specifically, we analyze the chemical shifting of the protons corresponding to the entrapped water and to the polar headgroup of the anionic surfactant (I and I', Scheme 1).

Protons of Entrapped Water. Figure 5 shows how the variation of $W_{0}$ affects the proton chemical shift values of entrapped water in both biobased AOT RMs. From the figure, a downfield shifting as the amount of water entrapped increases in both systems is detected; however, the value reached is not similar. For example, in p-cym/AOT RMs, changes from $4.02 \mathrm{ppm}$ up to $4.81 \mathrm{ppm}$ when the $W_{0}$ varied

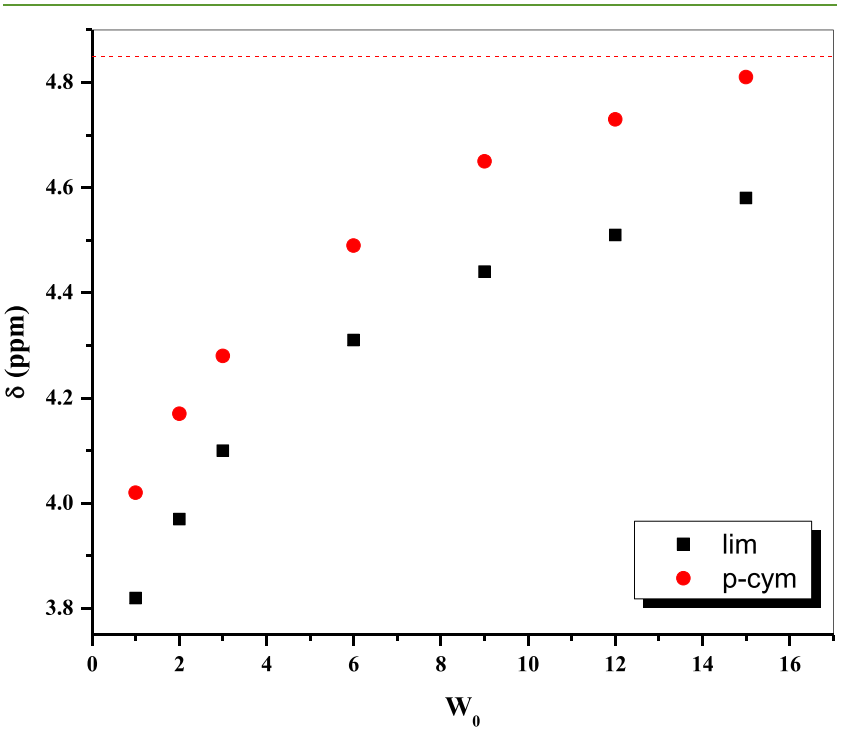

Figure 5. Effect of the water content on the chemical shifts of protons of entrapped water inside of both biobased RMs. $[\mathrm{AOT}]=0.2 \mathrm{M}$. For comparison, the value of neat water $(-)$ is also plotted. 
from 1 to 15 were observed. For $\lim /$ AOT RMs in the same $W_{0}$ range, the value changes from $3.82 \mathrm{ppm}$ up to $4.58 \mathrm{ppm}$. As it was noted from Figure 5, in the RMs formulated in p-cym the proton of water entrapped with the maximum $W_{0}$ evaluated appears to be quite similar to the neat water. ${ }^{30} \mathrm{~A}$ different situation for the system formulated with lim is observed, where the chemical shift is $4.58 \mathrm{ppm}$ at the $W_{0}$ maximum evaluated.

Compared with neat water, the position upfield of the protons of the entrapped water observed in our data was described previously for similar AOT RMs formulated in $\mathrm{C}_{6} \mathrm{D}_{6}{ }^{30,31}$ and in $\mathrm{C}_{6} \mathrm{D}_{12} \cdot{ }^{32}$ Disruption of the normal hydrogen bond structure of water as a consequence of the surfactant interaction was invoked to explain the detected shifts. As consequence of that, the water molecules interact less with each other, appearing at a more upfield region. As $W_{0}$ increases, the protons of water inside the organized media begin to recover the hydrogen bond structure of neat solvent. Thus, the chemical shifts of these $\mathrm{H}$ tend to the neat value. In our cases, both the biobased solvent and RMs show water molecules interacting with the anionic interface, and the hydrogen bond structure is disrupted by this phenomena. However, this interaction is quite different depending on the biobased solvent employed to prepare the RMs. Thus, a weaker interaction of water-surfactant at the interface in pcym/AOT as compared to that in $\lim /$ AOT RMs is suggested.

Protons of AOT Polar Head. The microenvironment created in the biobased solvent/AOT RMs can be monitored by following the chemical shift corresponding to the protons of the polar headgroup of the surfactant..$^{30,31}$ As it can be observed in Figure S9A and B, when the water content increases, an upfield shift of the signals of protons I and $\mathrm{I}^{\prime}$ of AOT (see label in Scheme 1) is observed. Thus, in p-cym/ AOT RMs the $\mathrm{H}$ I signal appears at $4.70 \mathrm{ppm}$ at $W_{0}=1$ and shifts to $4.55 \mathrm{ppm}$ at $W_{0}=15$, while the $\mathrm{H} \mathrm{I}^{\prime}$ signal appears at $3.52 \mathrm{ppm}$ at $W_{0}=1$ and shifts to $3.46 \mathrm{ppm}$ at $W_{0}=15$. For the AOT RMs formulated in lim, the signals changes in the same $W_{0}$ range from $4.41 \mathrm{ppm}$ up to $4.27 \mathrm{ppm}$ and from 3.25 to 3.19 ppm, respectively. Similar shifting was observed for AOT RMs generated using traditional nonpolar solvents. For example, Heatley ${ }^{30,31}$ reported that changing the $\mathrm{W}_{0}$ range from 1 to 5.3 in the systems $\mathrm{C}_{6} \mathrm{D}_{6} / \mathrm{AOT} /$ water resulted in the $\mathrm{H} \mathrm{I}$ signal shifting from $4.86 \mathrm{ppm}$, while the $\mathrm{H} \mathrm{I}^{\prime}$ shifts from 3.64 to 3.55 ppm in the same range of $W_{0}$. The increment of the spatial separation between anion AOT and its counterion, due to the interaction via hydrogen bond between the sulfonate group and the entrapped water, was invoked to explain these data.

Several arguments were invoked in the past to explain the different penetration of the external solvent in AOT RMs; one of these was the value of the molar volume $\left(V_{\mathrm{m}}\right)$ of the nonpolar solvents. For example, benzene has smaller $V_{\mathrm{m}}$ than $n$-heptane, and the behavior of AOT RMs generated in both nonpolar solvents was explained considering that the aromatic solvent penetrated more than the aliphatic. As it can be observed in Table 4, the $V_{\mathrm{m}}$ of p-cym is larger than lim; ${ }^{33}$ thus, $\lim \left(\operatorname{minor} V_{\mathrm{m}}\right)$ should penetrate the AOT interface more than p-cym, producing smaller RMs. However, our DLS results show a $D_{\text {app }}$ value two units smaller for the p-cym/AOT system in comparison to the $D_{\text {app }}$ value found for the lim/AOT system. This fact evidences that the $V_{\mathrm{m}}$ is not the appropriated factor to explain the results and that others such as polarity, viscosity, and molecular geometry (long or branched hydrocarbon chain) should be considered.
Table 4. Different Parameters Evaluated to Explain the External Solvent Aot Rms Penetration $\left(T=25^{\circ} \mathrm{C}\right)$

$\begin{array}{lccc}\text { solvent } & V_{\mathrm{m}}\left(\mathrm{cm}^{3} \mathrm{~mol}^{-1}\right)^{a} & \text { viscosity }(\mathrm{mPa} \mathrm{s}) & \pi^{* c} \\ \text { p-cym } & 184.8 & 0.82^{a} & 0.39 \\ \lim & 162.1 & 0.89^{b} & 0.16\end{array}$

${ }^{a}$ Values obtained from ref $33 .{ }^{b}$ Value obtained from ref $34 .{ }^{c}$ Values obtained from ref 15.

In this sense, the viscosity explains the nonpolar solvent interface penetration. Thus, if the solvent is more viscous, more penetration occurs into the interface. ${ }^{3}$

In our case, both biobased solvents have similar viscosity values (see Table 4). As it was mentioned above, the $\pi^{*}$ parameter was invoked before to explain facts such as why the maximal $W_{0}$ reached its value in the organized media. ${ }^{15}$ In this sense, as it is shown in Table 4, p-cym appears as more polar than lim, and consequently, its penetration to the interfacial region is larger (see Scheme 2).

Thus, the dissimilar penetration of both biobased solvents, which also perturb the water-surfactant interaction, can be explained due to the polarity having a stronger effect than the viscosity of these nonpolar solvents. Consequently, the p-cym/ AOT RMs are less interactive and smaller than those formulated in lim. Finally, new interfaces with unexplored physicochemical properties are generated due to the ability of the biobased solvent to penetrate or not into the AOT interface.

\section{CONCLUSIONS}

We demonstrated that biobased solvents such as p-cym and lim can be used to generate more sustainable AOT RMs. Interestingly, even the maximum amount of water dispersed is similar for both RMs, and the sizes of the systems are not identical, being that the RMs are formulated in lim larger than in p-cym.

In both the biobased solvent and RMs, the confined water showed that its hydrogen-bond structure was altered by the interaction with the interface; however, this interaction is quite different depending on the biobased solvent employed to prepare the RMs. Thus, the interaction of water-surfactant at the interface is weaker in p-cym/AOT than in lim/AOT RMs. We think that the different penetration of the external solvent to the interfacial region is the main reason for the facts observed. In this sense, the polarity is more than the viscosity or molar volume of these biobased solvents, explaining the dissimilar penetration suggested in both RMs. Finally, the possibility to formulate more friendly and versatile AOT RMs extends the future applications of these organized systems.

\section{EXPERIMENTAL SECTION}

Materials. The surfactant sodium 1,4-bis (2-ethylhexyl) sulfosuccinate (AOT) was provided by Sigma-Aldrich ( $>99 \%$ purity), and prior to use it was dried under vacuum. $p$-cymene ( $99 \%$ purity) and $(R)-(+)$ limonene (97\% purity), both provided by Sigma-Aldrich, were dried before use in a vacuum oven at $70{ }^{\circ} \mathrm{C}$ for at least $12 \mathrm{~h}$ and stored over molecular sieves. Labonco equipment model 90901-01 was used to generate Ultrapure water. 1-Methyl-8-oxyquinolinium betaine $(\mathrm{QB})$ was synthesized according to Ueda et al. ${ }^{2}$ Safranine $\mathrm{T}$ (Merck, $\geq 85 \%$ purity), $\mathrm{K}_{3}\left[\mathrm{Fe}(\mathrm{CN})_{6}\right]$ (Sigma-Aldrich, $99 \%$ purity), and $\mathrm{Ru}(\text { bpy })_{3} \mathrm{Cl}$ (Sigma-Aldrich, $97 \%$ purity) were used as received.

Methods. The preparation of the biobased solvents and AOT RMs, the absorption, the emission, and NMR experiments are fully described in the Supporting Information. 
Scheme 2. Effect to the External Solvent Penetration on the Biobased (A: p-cym and B: lim) AOT RMs

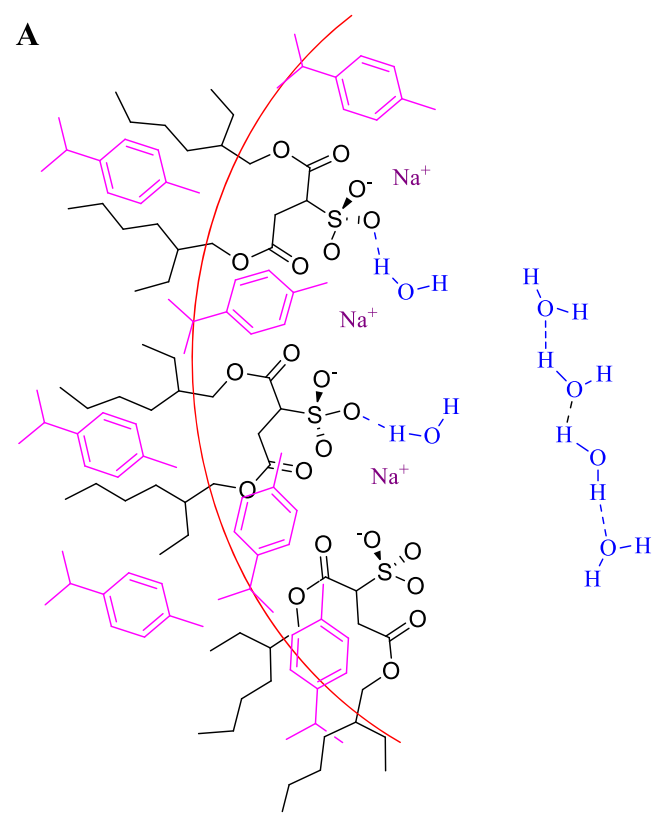

\section{ASSOCIATED CONTENT}

\section{st Supporting Information}

The Supporting Information is available free of charge at https://pubs.acs.org/doi/10.1021/acssuschemeng.9b06578.

Experimental procedure of the AOT RMs preparations; absorption, emission and NMR experiments (PDF)

\section{AUTHOR INFORMATION}

\section{Corresponding Authors}

Paulina Pavez - Facultad de Quimica y de Farmacia, Pontificia Universidad Católica de Chile, Santiago 6094411, Chile; ○ orcid.org/0000-0002-8891-3802; Email: ppavezg@uc.cl

R. Dario Falcone - Instituto para el Desarrollo Agroindustrial y de la Salud (IDAS), CONICET. Departamento de Quimica, Universidad Nacional de Río Cuarto, X5804BYA, Argentina; ○ orcid.org/0000-0002-0997-3437; Email: rfalcone@ exa.unrc.edu.ar

\section{Authors}

Mauricio Oyarzun - Facultad de Quimica y de Farmacia, Pontificia Universidad Católica de Chile, Santiago 6094411, Chile

Guillermo Oliva - Facultad de Quimica y de Farmacia, Pontificia Universidad Católica de Chile, Santiago 6094411, Chile

Complete contact information is available at:

https://pubs.acs.org/10.1021/acssuschemeng.9b06578

\section{Notes}

The authors declare no competing financial interest.

\section{ACKNOWLEDGMENTS}

Financial support from the Consejo Nacional de Investigaciones Cientificas y Técnicas (PIP CONICET 112-20150100283), Universidad Nacional de Río Cuarto (PPI-UNRC 2016-2019), Agencia Nacional de Promoción Científica y Técnica (PICT 2012-0232, PICT 2012-0526, and PICT 20150585), Ministerio de Ciencia y Tecnología, Gobierno de la

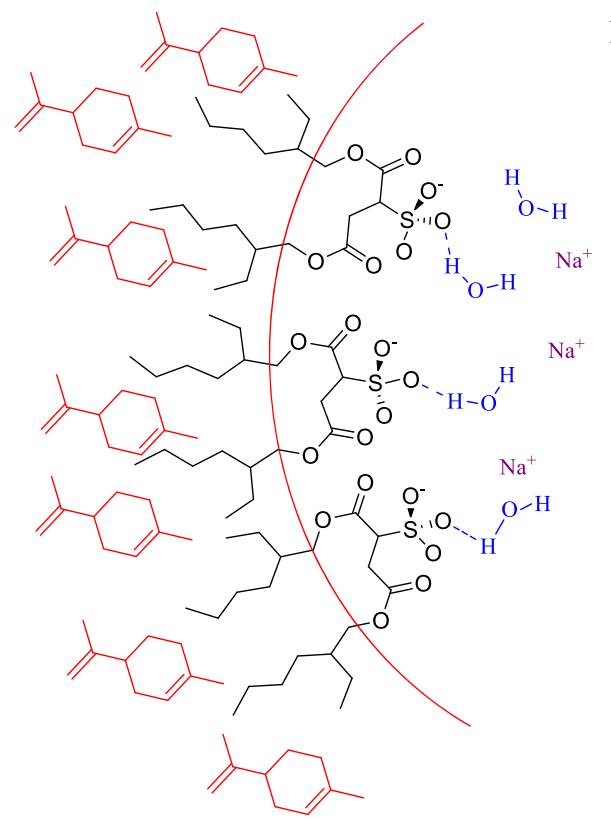

Provincia de Córdoba (PID2013 and PID2018), and the National Fund for Scientific and Technological Development (FONDECYT 1170976) is gratefully acknowledged. R.D.F. holds a research position at CONICET. G.O. thanks to CONICYT for a research fellowship.

\section{REFERENCES}

(1) Correa, N. M.; Silber, J. J.; Riter, R. E.; Levinger, N. E. Nonaqueous Polar Solvents in Reverse Micelle Systems. Chem. Rev. 2012, 112 (8), 4569-4602.

(2) Sun, X.; Bandara, N. Applications of Reverse Micelles Technique in Food Science: A Comprehensive Review. Trends Food Sci. Technol. 2019, 91, 106-115.

(3) Girardi, V. R.; Silber, J. J.; Mariano Correa, N.; Darío Falcone, R. The Use of Two Non-Toxic Lipophilic Oils to Generate Environmentally Friendly Anionic Reverse Micelles without Cosurfactant. Comparison with the Behavior Found for Traditional Organic NonPolar Solvents. Colloids Surf., A 2014, 457 (1), 354-362.

(4) Girardi, V. R.; Silber, J. J.; Falcone, R. D.; Correa, N. M. Micropolarity and Hydrogen-Bond Donor Ability of Environmentally Friendly Anionic Reverse Micelles Explored by UV/Vis Absorption of a Molecular Probe and FTIR Spectroscopy. Chem. Phys. Chem. 2018, 19 (6), 759-765.

(5) Kaur, M.; Singh, G.; Kumar, S.; Navnidhi; Kang, T. S. Thermally Stable Microemulsions Comprising Imidazolium Based Surface Active Ionic Liquids, Non-Polar Ionic Liquid and Ethylene Glycol as Polar Phase. J. Colloid Interface Sci. 2018, 511, 344-354.

(6) De, T. K.; Maitra, A. Solution Behaviour of Aerosol OT in NonPolar Solvents. Adv. Colloid Interface Sci. 1995, 59, 95-193.

(7) Dib, N.; Silber, J. J.; Correa, N. M.; Falcone, R. D. Combination of a Protic Ionic Liquid-like Surfactant and Biocompatible Solvents to Generate Environmentally Friendly Anionic Reverse Micelles. New J. Chem. 2019, 43 (26), 10398-10404.

(8) Bubic Pajic, N.; Nikolic, I.; Mitsou, E.; Papadimitriou, V.; Xenakis, A.; Randjelovic, D.; Dobricic, V.; Smitran, A.; Cekic, N.; Calija, B.; et al. Biocompatible Microemulsions for Improved Dermal Delivery of Sertaconazole Nitrate: Phase Behavior Study and Microstructure Influence on Drug Biopharamaceutical Properties. J. Mol. Liq. 2018, 272, 746-758.

(9) Gu, Y.; Jérôme, F. Bio-Based Solvents: An Emerging Generation of Fluids for the Design of Eco-Efficient Processes in Catalysis and Organic Chemistry. Chem. Soc. Rev. 2013, 42 (24), 9550-9570. 
(10) Clark, J.; Farmer, T.; Hunt, A.; Sherwood, J. Opportunities for Bio-Based Solvents Created as Petrochemical and Fuel Products Transition towards Renewable Resources. Int. J. Mol. Sci. 2015, 16 (8), 17101-17159.

(11) Paggiola, G.; Hunt, A. J.; McElroy, C. R.; Sherwood, J.; Clark, J. H. Biocatalysis in Bio-Derived Solvents: An Improved Approach for Medium Optimisation. Green Chem. 2014, 16 (4), 2107-2110.

(12) Clark, J. H.; Macquarrie, D. J.; Sherwood, J. A Quantitative Comparison between Conventional and Bio-Derived Solvents from Citrus Waste in Esterification and Amidation Kinetic Studies. Green Chem. 2012, 14 (1), 90-93.

(13) Jin, S.; Byrne, F.; McElroy, C. R.; Sherwood, J.; Clark, J. H.; Hunt, A. J. Challenges in the Development of Bio-Based Solvents: A Case Study on Methyl(2,2-Dimethyl-1,3-Dioxolan-4-Yl)Methyl Carbonate as an Alternative Aprotic Solvent. Faraday Discuss. 2017, 202 (0), 157-173.

(14) Pavez, P.; Oliva, G.; Millán, D. Green Solvents as a Promising Approach to Degradation of Organophosphorate Pesticides. ACS Sustainable Chem. Eng. 2016, 4 (12), 7023-7031.

(15) Abuin, E.; Lissi, E.; Jara, P. Effect of the organic solvent on the interfacial micropolarity of aot-water reverse micelles. J. Chil. Chem. Soc. 2007, 52 (1), 1082-1087.

(16) Marcus, Y. The Properties of Organic Liquids That Are Relevant to Their Use as Solvating Solvents. Chem. Soc. Rev. 1993, 22 (6), 409-416.

(17) Novaki, L. P.; El Seoud, O. A. Microscopic Polarities of Interfacial Regions of Aqueous Cationic Micelles: Effects of Structures of the Solvatochromic Probe and the Surfactant. Langmuir 2000, 16 (1), 35-41.

(18) Falcone, R. D.; Correa, N. M.; Biasutti, M. A.; Silber, J. J. Properties of AOT Aqueous and Nonaqueous Microemulsions Sensed by Optical Molecular Probes. Langmuir 2000, 16 (7), 3070-3076.

(19) Quintana, S. S.; Falcone, R. D.; Silber, J. J.; Correa, N. M. Comparison between Two Anionic Reverse Micelle Interfaces: The Role of Water-Surfactant Interactions in Interfacial Properties. Chem. Phys. Chem. 2012, 13 (1), 115-123.

(20) Odella, E.; Falcone, R. D.; Ceolín, M.; Silber, J. J.; Correa, N. M. Structural Characterization of Biocompatible Reverse Micelles Using Small-Angle X-Ray Scattering, 31P Nuclear Magnetic Resonance, and Fluorescence Spectroscopy. J. Phys. Chem. B 2018, 122 (15), 4366-4375.

(21) Ueda, M.; Schelly, Z. A. Reverse Micelles of Aerosol-OT in Benzene: 4: Investigation of the Micropolarity Using 1-Methyl-8Oxyquinolinium Betaine as a Probe. Langmuir 1989, 5 (4), 10051008.

(22) Nandi, S.; Bhattacharya, S. C. Alkanol Effects on Fluorescence Quenching of Safranine T by Thiourea in Reverse Micellar Medium of Aerosol-O-T in Heptane. Colloids Surfaces A Physicochem. Colloids Surf., A 2001, 186 (3), 179-187.

(23) Bhattacharya, S. C.; Nandi, S.; Moulik, S. P. Visible and Fluorescence Spectral Studies on the Interaction of Safranine $\mathrm{T}$ with Reverse Micelles of Triton X-100 and Tweens in Chloroform. J. Photochem. Photobiol., A 1996, 97 (1-2), 57-63.

(24) Chatterjee, S.; Nandi, S.; Bhattacharya, S. C. Interface of AOT/ Igepal CO720/Cyclohexane/Water Mixed Reverse Micelle by Spectroscopic Approach. Colloids Surfaces A Physicochem. Colloids Surf., A 2006, 279 (1-3), 58-63.

(25) Ghosh, S. K.; Khatua, P. K.; Bhattacharya, S. C. Physicochemical Characteristics of Reverse Micelles of Polyoxyethylene Nonyl Phenol in Different Organic Solvents. J. Colloid Interface Sci. 2004, 279 (2), 523-532.

(26) Maitra, A. Determination of Size Parameters of Water-Aerosol OT-Oil Reverse Micelles from Their Nuclear Magnetic Resonance Data. J. Phys. Chem. 1984, 88 (21), 5122-5125.

(27) Li, Q.; Li, T.; Wu, J. Electrical Conductivity of Water/Sodium Bis(2-Ethylhexyl) Sulfosuccinate/n-Heptane and Water/Sodium Bis(2-Ethylhexyl) Phosphate/n-Heptane Systems: The Influences of Water Content, Bis(2-Ethylhexyl) Phosphoric Acid, and Temperature. J. Colloid Interface Sci. 2001, 239 (2), 522-527.
(28) Evans, D. F.; Ninham, B. W. Molecular Forces in the SelfOrganization of Amphiphiles. J. Phys. Chem. 1986, 90 (2), 226-234.

(29) Moroi, Y.; Humphry-Baker, R.; Gratzel, M. Determination of Micellar Aggregation Number of Alkylsulfonic Acids by Fluorescence Quenching Method. J. Colloid Interface Sci. 1987, 119 (2), 588-591.

(30) Heatley, F. A 1H and 13C Nuclear Magnetic Resonance Study of the Conformation of Aerosol OT in Water and Hydrocarbon Solutions. J. Chem. Soc., Faraday Trans. 1 1987, 83 (2), 517-526.

(31) Heatley, F. A 1H Nuclear Magnetic Resonance Chemical-Shift Study of Inverted Microemulsions of Aerosol OT in Benzene and Cyclohexane. Partitioning of Water between Hydrocarbon and Aqueous Phases. J. Chem. Soc., Faraday Trans. 1 1988, 84 (1), 343.

(32) Stahla, M. L.; Baruah, B.; James, D. M.; Johnson, M. D.; Levinger, N. E.; Crans, D. C. $1 \mathrm{H}$ NMR Studies of Aerosol-OT Reverse Micelles with Alkali and Magnesium Counterions: Preparation and Analysis of MAOTs. Langmuir 2008, 24 (12), 6027-6035.

(33) Mackay, D.; Shiu, W.-Y.; Shiu, W.-Y.; Lee, S. C. Handbook of Physical-Chemical Properties and Environmental Fate for Organic Chemicals 2006, 1.

(34) Clará, R. A.; Marigliano, A. C. G.; Sólimo, H. N. Density, Viscosity, and Refractive Index in the Range (283.15 to 353.15$) \mathrm{K}$ and Vapor Pressure of $\alpha$-Pinene, d-Limonene, $( \pm)$-Linalool, and Citral Over the Pressure Range 1.0 KPa Atmospheric Pressure. J. Chem. Eng. Data 2009, 54 (3), 1087-1090. 